\title{
Study on the Current Situation and Countermeasures of Tourism Informatization in Shandong Province
}

\author{
Xiuyuan $\mathrm{Li}^{1, a,{ }^{*}}$, Huijian $\mathrm{Han}^{1, \mathrm{~b}}$ and Jinxi $\mathrm{Li}^{2, \mathrm{c}}$ \\ ${ }^{1}$ School of computer science and technology, Shandong University of Finance and Economics, \\ Jinan, Shandong, China \\ ${ }^{2}$ School of Information Science and Engineering, Harbin Institute of Technology (Weihai), Weihai, \\ Shandong, China

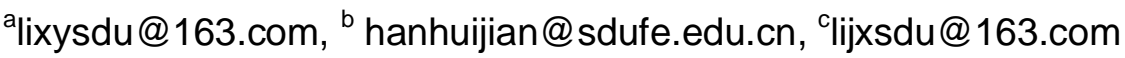 \\ ${ }^{*}$ Corresponding author
}

Keywords: Tourism, Informatization, Current Situation, Countermeasure.

\begin{abstract}
At present, tourism has been in the forefront of national economic construction. Promoting the transformation of tourism production mode, management mode, marketing mode and consumption mode with information technology can better stimulate the driving force and vitality of tourism development and better undertake its mission of building a well-off society in an all-round way. Taking 11 5A scenic spots in Shandong Province as an example, this paper analyzes the current situation of tourism scenic spot informatization and put forward decision-making suggestions for informatization construction. In this paper, the quantitative analysis method is utilized to provide new ideas for the empirical study of tourism. The decision-making suggestions in this paper can be used for reference in the development planning of tourism and other related industries in other provinces and cities.
\end{abstract}

\section{山东省旅游业信息化的现状及对策研究}

\author{
李秀媛 ${ }^{1, a,{ }^{*}}$ ，韩慧健 ${ }^{1, b}$ ，李锦熙 $2, c$ \\ ${ }^{1}$ 山东财经大学计算机科学与技术学院, 济南, 山东, 中国 \\ 2 哈尔滨工业大学 (威海) 信息科学与工程学院, 威海, 山东, 中国 \\ alixysdu@163.com, ${ }^{\mathrm{b}}$ hanhuijian@sdufe.edu.cn, ${ }^{\mathrm{C} l i j x s d u @ 163 . c o m ~}$ \\ “通讯作者
}

关键词：旅游业; 信息化; 现状; 对策

中文摘要. 目前, 旅游业已经走在国民经济建设的前沿。利用信息技术推进旅游生产方式、管 理模式、营销模式和消费形态的转变, 能更好地激发旅游业的发展, 使其更好地承担全面建设 小康社会的使命。本文以山东省 11 个 $5 \mathrm{~A}$ 级景区为例，分析景区的信息化现状，提出了信息化建 设的决策建议。本文采用量化分析的研究方法, 为旅游业的实证研究提供了新思路。文中的决 策建议具有一定的通用性，在其他省市旅游业及相关产业发展规划中亦具有借鉴意义。 


\section{1. 引言}

随着我国经济进入新常态, 要破解发展难题, 须牢固树立并切实贯彻创新、协调、绿色、 开放、共享的发展理念（简称：五大发展理念）。旅游业的产业特点与五大发展理念高度契 合, 而且作为优势产业, 旅游业对国民经济和社会就业的贡献度均超过 $10 \%$ 。旅游业已经成为 国家战略性支柱产业，是国民经济建设的排头兵。当前我国正处在全面建成小康社会的决胜 阶段，必然会对旅游业发展提出更高要求，也给旅游业信息化发展带来重大机遇。

\section{2. 旅游信息化发展现状}

\section{1 旅游信息化概述}

据百度百科.科普中国定义，信息化是指培养、发展以计算机为主的智能化工具为代表的 新生产力, 并使之造福于社会的历史过程。[1]林毅夫等从经济学的角度指出: “所谓信息化, 是指建立在IT产业发展与IT在社会经济各部门扩散的基础之上，运用IT改造传统的经济、社 会结构的过程”。[2]关于旅游信息化, 尚未有公认的权威定义。本文结合已有相关文献, 并分 析国家旅游局2017年3月9日印发的《“十三五”全国旅游信息化规划》相关内容，给出旅游信 息化定义。旅游信息化是指将信息技术应用于旅游产业，进行跨界融合，推进旅游生产方式、 管理模式、营销模式和消费形式的转变, 全面提升旅游产业质量效益和核心竞争力, 更好满 足游客个性化服务需求。旅游的信息化包括旅游的数字化、旅游的网络化、旅游的数据化、 旅游的智能化。（目前这一词条的定义已被百度百科采纳）

\section{2 相关研究综述}

目前, 关于旅游业信息化的研究已取得一些进展。邹统钎等阐述我国旅游业信息化进程, 并展望旅游业未来发展 ${ }^{[3]}$; 刘治彦等分析我国智慧旅游发展现状, 提出智慧化发展目标, 并给 出决策建议 ${ }^{[4]}$; 曲凯分析旅游营销活动中大数据的应用情况并给出合理化建议 ${ }^{[5]}$; 黄松等提出 一个包含三级指标的智慧旅游城市评价体系 ${ }^{[6]}$; 王冠孝等构建区域旅游业与信息化耦合协调 评价指标体系, 并对 31 个省份的耦合水平定量评价 ${ }^{[7]}$ 。上述研究的地域范围是全国, 还有一些 研究成果是关于省域旅游业的。范生万等探讨了新技术环境下, 安徽省旅游信息化现状和对 策 ${ }^{[8]}$ 。关于山东省旅游业信息化的研究文献较少, 赵传松研究山东省旅游业全域发展模式, 其 中有很少量关于信息化建设的内容 ${ }^{[9]}$ 。

已有文献中的研究方法大多采用定性分析，少部分采用定量分析，几乎没有文献从技术 角度进行定量分析。考虑到信息化是将信息技术应用于旅游产业，因此本文侧重从技术的角 度定量分析山东省旅游业信息化现状，并给出决策建议。

\section{3 山东省旅游信息化发展现状}

山东省地理位置优越、经济基础雄厚、社会环境良好、旅游资源丰富，旅游消费收入和 接待人次都位列全国前茅。山东省拥有 $\mathrm{A}$ 级景区 1173 个, 其中 $5 \mathrm{~A}$ 级景区 11 家。为准确又简单 说明山东省旅游信息化现状, 在对省内 $4 \mathrm{~A} 、 5 \mathrm{~A}$ 景区的调查了解并搜集资料之后, 仅将 11 个 $5 \mathrm{~A}$ 景区的信息化情况整理成表，如表1所示。

表1中，5A景区的信息化衡量的指标主要通过搜集景点网站资料和实地调研获得。为便于 量化，将信息化的支撑资料分为7类。其中，景点信息类包括：网站是否有景点图文介绍（简 称：图文）、视频介绍或全景视图（简称：视频）、旅游导览或攻略（简称：导览）信息；信 息查询类包括：景点门票价格（简称：票价）、交通线路（简称：交通）、景点天气或日出时 间或大海潮汐（简称：天气）的信息；电子商务类包括是否提供网上购门票（简称：购票）、 订酒店服务（简称：住宿）; 客户服务类包括是否可以 24 小时在线互动（简称：在线）、网上 留言回复（简称：留言）、提供热线电话（简称：电话），提供手机等移动客户端服务（简 称：移动）; 信息推送是指能否实时推送景点活动相关信息; 电子政务类是指能否及时联系 
到景点管理机构或负责人; 考虑到山东省文化资源丰厚，非常重视文化和旅游资源结合，因 此也考察是否提供文化资源信息。表中单元格内的“Y”表示有相关信息，“ $\mathrm{N}$ ”表示没有相关信 息, “ $\mathrm{Y}^{+} ”$ 表示可以链接到网站外资源, 且能实现功能; “ $\mathrm{Y}^{-”}$ 表示虽然可以链接资源, 但不能 实现功能或者表示信息不全。

表1山东省5A景区信息化程度一览表

\begin{tabular}{|c|c|c|c|c|c|c|c|c|c|c|c|c|c|c|c|c|}
\hline \multirow{4}{*}{$\begin{array}{l}\text { 序 } \\
\text { 号 }\end{array}$} & \multirow{4}{*}{ 景区名 } & \multicolumn{15}{|c|}{ 信息化服务 } \\
\hline & & \multicolumn{3}{|c|}{ 景点信息类 } & \multicolumn{3}{|c|}{ 信息查询类 } & \multicolumn{2}{|c|}{$\begin{array}{l}\text { 电子商 } \\
\text { 务类 }\end{array}$} & \multicolumn{4}{|c|}{ 客户服务类 } & \multirow{3}{*}{$\begin{array}{l}\text { 信 } \\
\text { 息 } \\
\text { 推 } \\
\text { 送 }\end{array}$} & \multirow{3}{*}{$\begin{array}{l}\text { 电 } \\
\text { 子 } \\
\text { 政 } \\
\text { 务 }\end{array}$} & \multirow{3}{*}{$\begin{array}{l}\text { 文 } \\
\text { 化 } \\
\text { 资 } \\
\text { 源 }\end{array}$} \\
\hline & & 图 & 视 & 导 & 票 & 交 & 天 & 购 & 住 & 在 & 留 & 电 & 移 & & & \\
\hline & & 文 & 频 & 览 & 价 & 通 & 气 & 票 & 宿 & 线 & 言 & 话 & 动 & & & \\
\hline 1 & $\begin{array}{c}\text { 济南（天下第 } \\
\text { 一泉景区） }\end{array}$ & $\mathrm{Y}$ & $\mathrm{Y}$ & $\mathrm{Y}$ & $\mathrm{N}$ & Y & $\mathrm{N}$ & $\mathrm{N}^{-}$ & $\mathrm{N}$ & $\mathrm{N}$ & $\mathrm{Y}$ & Y & Y & Y & Y & Y \\
\hline 2 & $\begin{array}{c}\text { 青岛（崂山风 } \\
\text { 景区） }\end{array}$ & $\mathrm{Y}$ & Y & $\mathrm{Y}$ & Y & Y & Y & Y & $\mathrm{Y}^{-}$ & $\mathrm{N}$ & Y & Y & Y & Y & Y & Y \\
\hline 3 & $\begin{array}{c}\text { 崽庄（台儿庄 } \\
\text { 古城景区） }\end{array}$ & $\mathrm{Y}$ & $\mathrm{Y}$ & $\mathrm{Y}$ & Y & Y & Y & $\mathrm{N}$ & $\mathrm{N}$ & $\mathrm{Y}$ & Y & Y & Y & Y & Y & $\mathrm{Y}$ \\
\hline 4 & $\begin{array}{l}\text { 济宁（曲阜明 } \\
\text { 故城旅游区） }\end{array}$ & $\mathrm{Y}$ & $\mathrm{Y}$ & $\mathrm{Y}$ & Y & $\mathrm{N}$ & $\mathrm{N}$ & $\mathrm{N}$ & $\mathrm{N}$ & $\mathrm{N}$ & Y & $\mathrm{N}$ & $\mathrm{N}$ & Y & $\mathrm{N}$ & Y \\
\hline 5 & $\begin{array}{c}\text { 泰安（泰山风 } \\
\text { 景名胜区） }\end{array}$ & Y & Y & Y & Y & Y & Y & Y & $\mathrm{N}$ & Y & Y & Y & Y & Y & Y & $\mathrm{Y}$ \\
\hline 6 & $\begin{array}{c}\text { 潍坊（青州古 } \\
\text { 城旅游区） }\end{array}$ & $\mathrm{Y}$ & Y & Y & Y & Y & $\mathrm{N}$ & $\mathrm{N}$ & $\mathrm{N}$ & $\mathrm{N}$ & $\mathrm{N}$ & $\mathrm{N}$ & $\mathrm{N}$ & $\mathrm{Y}$ & Y & Y \\
\hline 7 & $\begin{array}{c}\text { 临沂（沂蒙山 } \\
\text { 旅游区） }\end{array}$ & $\mathrm{Y}$ & $\mathrm{N}$ & $\mathrm{Y}$ & Y & Y & $\mathrm{N}$ & Y & Y & $\mathrm{N}$ & $\mathrm{N}$ & Y & $\mathrm{N}$ & $\mathrm{Y}$ & $\mathrm{N}$ & Y \\
\hline 8 & $\begin{array}{c}\text { 烟台（龙口南 } \\
\text { 山景区） }\end{array}$ & Y & Y & $\mathrm{N}^{-}$ & Y & $\mathrm{N}$ & $\mathrm{N}$ & $\mathrm{Y}^{+}$ & $\mathrm{Y}^{+}$ & $\mathrm{N}$ & $\mathrm{N}$ & Y & $\mathrm{N}$ & Y & $\mathrm{N}$ & Y \\
\hline 9 & $\begin{array}{c}\text { 烟台（蓬莱阁 } \\
\text { 旅游区） }\end{array}$ & Y & Y & Y & Y & Y & $\mathrm{N}$ & Y & Y & Y & $\mathrm{N}$ & Y & Y & $\mathrm{Y}$ & $\mathrm{N}$ & Y \\
\hline 10 & $\begin{array}{c}\text { 威海 (华夏城 } \\
\text { 景区) }\end{array}$ & Y & $\mathrm{N}$ & $\mathrm{Y}^{-}$ & Y & Y & $\mathrm{N}$ & $\mathrm{N}$ & $\mathrm{N}$ & $\mathrm{N}$ & $\mathrm{N}$ & $\mathrm{Y}$ & $\mathrm{N}$ & $\mathrm{N}$ & $\mathrm{N}$ & $\mathrm{N}$ \\
\hline 11 & $\begin{array}{c}\text { 威海 (刘公岛 } \\
\text { 景区) }\end{array}$ & $\mathrm{Y}$ & $\mathrm{Y}$ & $\mathrm{Y}$ & Y & $\mathrm{Y}$ & $\mathrm{Y}$ & $\mathrm{Y}^{+}$ & $\mathrm{N}$ & $\mathrm{N}$ & $\mathrm{Y}$ & $\mathrm{Y}$ & Y & $\mathrm{Y}$ & $\mathrm{Y}^{-}$ & $\mathrm{Y}$ \\
\hline
\end{tabular}

表1中，11个5A景区除华夏城景区（景点信息由好客山东网提供）和青州古城区（景点信 息由搜狐网提供）外，都已自建网站，其中有6个景区还提供移动客户端服务。这说明景区管 理的网络信息化已基本实现。除去济南天下第一泉风景区在市区, 潍坊青州古城旅游区是免 费游览， 11 个景区中有 6 个景区门票可以网上购买，有5个景区还提供网上订酒店业务。这表 明景区电子支付技术的运用率超过一半。所有景区都没有提供实时游客数据。另外，个别景 区仅提供全景区的VR(Virtual Reality)图，但没有具体景点的VR图。

分析山东省 $5 \mathrm{~A}$ 景区的旅游业信息化现状可以发现：山东省的 $5 \mathrm{~A}$ 景区已基本实现网络信息 化, 移动互联网技术和电子支付技术有待进一步推广，物联网、大数据、人工智能等技术的 落地是旅游业下一步发展的重点。令人称赞的是, 山东省很重视文化的引领作用, 文化和旅 游深度融合效果明显。不过, 大多数景区的网站没有提供管理机构和负责人的联系方式, 管 理部门的服务意识有待提高。另外, 通过网上资料收集和实地考察4A级景区信息化相关信息, 发现4A景区的信息化程度要略差些。 


\section{3. 旅游信息化决策建议}

基于上述分析，对于如何全面提升山东省旅游业信息化水平给出如下建议:

首先, 建设一体化云平台, 释放大数据潜能。旅游业信息化是不断数字化、网络化、数 据化、智能化的过程。网络化建设已经基本完成，而智能化的前提是海量的数据收集整理和 分析挖掘。目前景区数据的采集不充分，而且不能共享，无法发挥数据资源的价值。若能建 成全省旅游数据云平台，景区的人流量、车流量信息，游客身份、消费信息，景区商家的销 售信息等都集中到云端, 就能用数据分析挖掘技术进行处理, 才能对突发情况及时应急处理, 更好地进行景区管理和监控，也有利于制定旅游业发展的规划和决策。

其次, 搭建旅游电商平台, 提供方便快捷服务。旅游业发展的目标之一是为游客提供方 便快捷、个性化的服务。搭建旅游电商平台, 营销成本降低, 游客可以网上比价, 随时随地 订酒店、购门票、买旅游纪念品, 企业也能获取游客信息, 提供更个性化服务。不仅如此, 电商平台能提升游客的忠诚度，有利于进一步推广其他金融科技类产品。

最后，深入开展政企校合作，促进产学研发展。“十三五”期间，旅游信息化面临重大机 遇, 也会遇到不少挑战。要重视政府政策引导和资金支持, 通过深入开展政企校合作, 充分 发挥学校人才优势和智力优势, 加强顶层设计, 全域布局, 企业落实, 促进产学研发展, 促 进、优化旅游业信息化建设, 加快建设新型旅游强省。

\section{4. 结束语}

用云计算、物联网、大数据等现代信息技术推动旅游业现代化发展，是旅游业发展的必 然趋势。既是适应信息化时代的必然选择，也是全域旅游发展的客观要求，更是满足游客需 求的内在要求。

\section{References}

[1] Weihong Dang, The application of informatization in human resource management, Heilongjiang Chronicles, vol.18(13), pp.118-119, 2015.

[2] Bei Yang, Beijing Rural Tourism Informatization Research, Chinese Academy of Agricultural Sciences, pp.10, 2013.

[3] Tongqian Zou, Mengqian Chang, The process and Prospect of tourism informatization in China, China Tourism News, 2019/06/04.

[4] Zhiyan Liu, Junyu Li, Bo Shang, Chengye Li, Development status and trend of smart Tourism, Enterprise economy, http://kns.cnki.net/kcms/detail/36.1004.F.20191014.1348.019.html, 2019.

[5] Kai Qu, Discussion on the application of big data in the global tourism intelligent marketing, tourism tribune, vol. 32(10), pp. 9-10, 2017.

[6] Song Huang, Yanlin Li, Pingjuan Dai, Evaluation of tourism competitiveness of smart tourism cities, Journal of Geography (Chinese version), vol.72(2), pp. 242-255, 2017.

[7] Guanxiao Wang, Like Liang, Feng Li, Siyuan Jiang, Xiaowei Duan, An empirical research on the coupling coordinative relationship between regional tourism and informatization, Journal of Natural Resources, vol. 31(8), pp. 1339-1350, 2016.

[8] Shengwan Fan, Liang Guo, Research on the current situation and Development Countermeasures of Anhui tourism informatization under the new technology environment, Journal of Changsha Railway University (SOCIAL SCIENCES), vol. 15(2), pp. 15-17, 2014. 
[9] Chuansong Zhao, Study on sustainable evaluation and development model of comprehensive tourism in shandong province, Shandong Normal University, pp.168-169, 2019. 